\title{
Next year in Jerusalem: psychotherapy training for tomorrow's consultants ${ }^{\dagger}$
}

\author{
Sally Mitchison
}

Abstract The Royal College of Psychiatrists' requirements for psychotherapy training and the role of the local psychotherapy tutor are summarised. Practical issues concerning the provision of this training are discussed, taking into account the anxieties that trainees experience. Suggestions are made about conducting case discussion groups, providing case supervision in small groups, locating short cases and arranging group and systemic therapy experience.

There has unfortunately been a delay of over a year between submission of the final version of this article and its publication. The article therefore does not address directly or in detail questions of how training may need in the future to be adapted to accommodate the new postgraduate curriculum. Ed.

The purpose of the Royal College of Psychiatrists' revised psychotherapy guidelines (Royal College of Psychiatrists, 2004) is that all senior house officers (SHOs) in psychiatric training gain an experiential understanding of the practice, effects and scope of the psychotherapies commonly available in the National Health Service. A further aspiration is that psychotherapy training will assist trainees to acquire the key attributes of good psychiatrists: a basic understanding of group dynamics, a critical awareness of their emotional responses to situations and the capacities to communicate well and to listen.

The syllabus of the Royal College of Psychiatrists' Membership (MRCPsych) examinations covers a basic understanding of psychodynamic, cognitive and systemic models. Experiential learning should be supplemented by reading. Trainees are expected to achieve specific training requirements (Box 1) and they are expected to use their logbooks to record their psychotherapy training. The local psychotherapy tutor, usually a consultant psychiatrist in psychotherapy, is responsible for coordinating and facilitating this training, drawing attention to gaps in provision and to trainees in difficulty. This

${ }^{+}$For a companion article see pp. 284-290, this issue.

\section{Box 1 Psychotherapy training requirements}

- Interview skills

- Psychotherapeutic formulation of psychiatric disorder

- A minimum of three short cases (12-16 sessions), each using a different therapeutic model: psychodynamic, cognitivebehavioural or integrative psychotherapy. The latter includes:

- supportive therapy

- interpersonal therapy

- cognitive analytic therapy

- One long case (12-18 months) in any model

- Some experience of either group therapy or couple, family and systemic therapy

can feel like providing for a multitude with only two loaves and five fishes - and invariably some of the multitude turn out to be vegetarian or gluten sensitive.

The purpose of this article is to pass on experience gained in catering for trainees' needs, helping them negotiate a satisfactory balance in their work between training and service and at the same time providing good enough therapy for their patients. This is currently unachievable without a miracle but may become more attainable under Modernising Medical Careers (Bhugra, 2005, 2006).

Currently, trainees' access to supervised training therapies varies considerably. For instance, in the

Sally Mitchison is a group analyst and a consultant psychiatrist in psychotherapy (Upper Poplars, Cherry Knowle Hospital, Ryhope, Sunderland SR2 ONB, UK. Email: sally.mitchison@stw.nhs.uk). She is responsible for the psychotherapy service in Sunderland. She previously worked in the same locality in a special responsibility consultant post, split between psychotherapy and general adult psychiatry. 


\section{Box 2 Components of psychotherapy} training

- Interview skills training

- Case discussion/Balint group

- Specific training in a particular model of therapy

- Supervised experience of delivering therapy in each model

Northern Deanery (the Northeast), most SHOs completed their long cases though not their three short cases (Carley \& Mitchison, 2006). But in the Northwestern Deanery (the Northwest) a third of SHOs surveyed had not undertaken any supervised therapy (Duddu \& Brown, 2004). Although the delivery of the 2004 training requirements has not been systematically studied, a survey in late 2004 elicited responses from six regions: Mersey, Oxford, North West Thames, the North West, the Northeast and the Southwest (A. Clark, 2005, personal communication). Clark's survey showed considerable variation between regions. Many were experiencing difficulties in providing supervision for cognitive-behavioural therapy (CBT) and integrative psychotherapies, and in the provision of group and systemic therapies, as well as finding it hard to identify patients suitable for brief psychotherapies. Much depends on the relative maturity and political strength of local psychological therapy services and in some areas of the country there is no local service.

This article is concerned with how to deliver the training rather than whether it is currently being delivered. It is based on my own experience of what can be achieved in a district service not attached to a teaching hospital, with a single consultant psychiatrist in psychotherapy and a catchment population of 330000. First, I consider the different components of psychotherapy training, listed in Box 2, then I comment on how to deliver the training requirements shown in Box 1.

\section{Trainees' anxieties}

Steering trainees through their psychotherapy training is rewarding but demanding. As in psychotherapy, success depends in part on developing an awareness of trainees' anxieties. These differ from those of the coordinating tutor, which focus on practicalities and logistics: the flow of patients and trainees and coordination of supervision. Most trainees take these practicalities for granted and the successful tutor is able to develop trainees' awareness gradually while attending behind the scene to the inevitable glitches and crises.

Passing the MRCPsych represents trainees' biggest anxiety. For those with limited UK registration there can be an urgency about doing this that supersedes all other concerns. Psychotherapy training is mandatory for schemes rather than individuals, and trainees have lost little time in appreciating this: they want to complete their training successfully, especially their long case, but passing their examinations comes first. This is so all-consuming a concern that some may not pause to think before offering it to patients in therapy as an explanation for breaks or altered therapy arrangements.

Trainees are also understandably anxious to succeed with their cases. If their patients drop out of therapy or fail to get better, trainees tend to see this as a reflection on them or, defensively, as a failure of their supervisor. In common with patients, they find it hard to think of responses in therapy as resulting from many factors. Only in retrospect can they regard difficulties and derailments in therapy as a useful part of the learning process.

A further common anxiety for trainees is that the inadequacy they feel will become shamefully evident and they will be shown up in front of their peers (Das et al, 2003). Rivalry in a year group can stimulate trainees to work towards mastery and maybe even do some reading - not something that many undertake readily on top of long hours and exam preparation - but it can also precipitate a destructive, downward cycle of declining self-esteem and demoralisation. Adults learn in different ways and at different rates and there can be hidden, inner resistances to developing greater psychological understanding and a capacity for reflection. Many trainees feel not only somewhat bewildered by psychodynamic ideas but exasperated at being expected to become adept at a further, different way of thinking about human beings. Encouraging a culture of open discussion in their training and supervision groups will make it easier for negative feelings and experiences to be aired, shared and put into perspective.

\section{Interview skills training}

This basic training is sometimes overlooked. It should be taken up by each educational supervisor, preferably through video recordings of interviews with patients. Role play with a trainee's year group is a poor substitute because of the rivalries and tensions that can be present in the cohort. 'Expert' patients can play a training role (Ikkos, 2003) and so can actors, especially those who regularly participate in clinical examinations. 


\section{Case discussion and Balint groups}

These small groups of trainees in their first 6-12 months of psychiatric experience are usually conducted by a consultant psychiatrist in psychotherapy. They can also, valuably, be led by clinical psychologists, specialist registrars in psychotherapy and adult psychotherapists. Each professional background brings to the task strengths but also blind spots.

Case discussion groups can provide an opportunity for trainees to experience the importance of continuity and the safety that comes from belonging to a closed group meeting, held weekly in the same place and at the same time. Some are run on a Balint (1957) model (Das et al, 2003; Fitzgerald \& Hunter, 2003); others are based on structured teaching (Blackwell \& Rimmer-Yehudai, 2001). There is scope for different teaching styles but personal experience suggests that the group leader should start and finish promptly, take a register and investigate unexcused absences, liaise with educational supervisors if trainees are consistently absent or paged during the group meetings and be prepared to supplement teaching points from a range of papers for beginners (Box 3 lists my personal favourites). It is difficult to run a successful case discussion group as a visitor from another locality unfamiliar with local systems and trainers.

Psychotherapy tutors may run these groups or, if not, may expect feedback on trainees from whoever does. This can help considerably in arranging individual sequences of further training. But this expectation creates an ethical dilemma for more Balint-oriented group leaders: should trainees' doubts, hesitations and difficulties be communicated to the tutor or held within the group?

There are also practical considerations that can help or hinder the group's development. Even where it has been possible to reach agreement on a protected time for postgraduate psychotherapy training it is unrealistic to expect trainees never to be paged during the group meeting (Wildgoose et al, 2002); they must have a telephone they can use in privacy. If they drive to the group they must be able to park. Some will need authorisation to use hospital transport. Medical students and doctors on clinical attachments may wish to join but they will not usually be in a position to bring cases for discussion. Their short-term presence may add value to the group but could reduce the sense of safety and mutual support that it so important if the group is to function well. The advent of foundation trainees raised questions about how to accommodate those starting 3- or 4-month postings at different points in the year. This has not proved straightforward.

For most trainees the case discussion group will be their first introduction to psychotherapy teaching.

\section{Box 3 Some recommended papers for case} discussion groups

- Bateman \& Holmes (1995: pp. 76-94), on defence mechanisms

- Campbell \& Hale (2001), on unconscious fantasies concerning suicide

- Fraiberg et al (1980), on identification with the aggressor, isolation of affect and transgenerational repetitions

- Malan (1979), on male Oedipal issues (pp. 54-72) and psychodynamic understanding of depression (pp. 166-184)

- Miller (1999), on very early developmental needs and the origins of good-enough object relating

- Segal (1986: pp. 37-49), on the richness of unconscious phantasy

- Watts \& Morgan (1994), on repeating a history of rejection, transference and countertransference

The experience of thinking about the dynamic unconscious and especially unconscious motivation can be deeply disturbing to young doctors, who have often scarcely considered why they have chosen to train as psychiatrists. Although in previous posts they will have had to deal with difficult or distressed patients, few will have had personal experience of failure, rejection or early abuse. This makes it difficult for them to empathise readily with their patients. Most will not yet be parents and will have little experience of young children and their development. When trainees discuss patients who have got under their skin - characteristically, those with borderline personality disorder - they tend to find the discussions stimulating, even exhilarating, but also quite disturbing. The group needs to feel safe enough for both idealistic views and difficult feelings to be expressed but there are also key concepts to be understood: defences, developmental issues and stages, object relations and their repetition in transference, countertransference, acting out and the repetition compulsion.

These ideas are always grasped better when linked to clinical experiences. Most SHOs will be in posts where they are expected to assess, advise and, on inpatient units, help manage many extremely difficult personalities. They find it easier to acknowledge being 'upset' by the patients they encounter than that some of these patients provoke in them anger and even retaliatory urges. It is easy to forget how very disturbing initial encounters with suicidality can be. Trainees find it easier to acknowledge their anxiety or fear of a completed suicide than the anger 
that suicidal acts create in all of us, having come into medicine to save lives.

\section{Training in the different models of therapy}

Local courses designed to prepare trainees for the MRCPsych examinations usually provide a basic grounding in the concepts used in CBT, psychoanalytic thinking (though often only up to the late 1940s) and the development of systemic family therapy. Although valuable, such an education does not equip trainees with the understanding they need to start working with patients in a particular model of therapy.

Psychotherapy tutors have the difficult task of establishing what exactly is taught on their local course. It is disquieting that some courses do not have a detailed syllabus. Where a syllabus exists, there is seldom any means of knowing if it is being adhered to. It is often best to assume that no practical training in any model is provided. Some models lend themselves better to formal, didactic instruction than others. Basic instruction in interpersonal therapy, for example, can be covered in a day, although the logistics of coordinating shifts and leave so as to ensure that all the trainees who need the instruction attend on a given day can be time-consuming and frustrating. Cognitive analytic therapy (CAT) trainers have also established a tradition of 1- and 2-day introductory workshops. The basic techniques of brief, focal CBT for patients with uncomplicated depression can be similarly taught, although schemabased work is less amenable to such an approach.

Training for psychodynamic therapy can be included in case discussion groups, but trainees may not be ready for it at that stage. It is often easier for trainees to move on from case discussion to a supportive therapy or participating in a patient group before embarking on CBT or a psychodynamic therapy.

Some supervisors introduce novice therapists to the supervision group for a number of weeks before they take on a case, so that they can pick up the basics of how psychodynamic therapy is done. This may help the supervisor match each trainee with a suitable patient. It is much easier to do this and to supervise well if the supervisor has assessed the patient personally. Sometimes this requires a change in departmental procedures. Although it departs from an inductive tradition, there is an argument for providing some individual training within a supervision group for the new member about to take on a case. This training should be practical, focusing on what to establish during the initial meeting with the patient, how to act in the first few sessions and why to approach matters this way. The advantage of running through this in the supervision group is that other trainees can contribute from their own experience, reflecting on it in the process. The new trainee is rather more likely to remember fellow trainees' experiences than the supervisor's instructions.

Supervision may entail audio or video recording of sessions and not all patients - or supervisors - accept this. It seems likely that the Postgraduate Medical Education and Training Board will include close scrutiny of training therapies as part of workplacebased assessment. In anticipation of this, trusts may need to purchase and set up tape recorders or video equipment. Difficult though it may be for trainees and patients to accept audio- or videotaping and time-consuming though reviewing such tapes is for the supervisor, patients usually find it preferable to directly observed assessment.

\section{Case supervision}

Although trainees can find it difficult moving from one therapy modality to another, the differences in the practice of case supervision are less than one might imagine. The experienced supervisor will be used to patients changing their minds about therapy, finding work, moving house, losing their means of transport or finding their circumstances altered in other ways that affect their availability for therapy. Similarly, and predictably, trainees go on night shift, have study leave, fall ill and take long periods of leave. They usually develop considerable commitment to their training cases but because their psychotherapy practice is a training requirement, most initially expect their supervisor and patient to understand and work round their unavailability. It is better if they hear from other, more experienced members of the supervision group rather than from the supervisor that their absence will have an impact on the therapy.

Other, more senior members of the supervision group may draw new trainees' attention to protocols established locally for conducting psychotherapy, but this cannot be counted on. Successive generations of trainees make the same mistakes, usually because they fail to really think about what taking on a psychotherapy case will mean - it can seem at first like just another hoop to jump through. It is wise to produce written guidelines for these and other 'visiting' therapists (see Box 4).

Psychiatrists in training have to learn to function as therapists, not psychiatrists, listening without taking contemporaneous notes (except in CBT) and refraining from being too active or from solving patients' problems for them. They may benefit from reading Rogers (1951). 
Group learning is more effective when trainees are at different stages in their therapies and when nonmedical trainees are included. The group dynamics are important and supervisors must be prepared to protect the supervisory space from intrusion and from spectators, including trainees who for various reasons are not actually conducting a therapy. Other group members will, with encouragement, gain the confidence to explain to fellow trainees when they are making elementary errors, although the supervisor may need to step in occasionally to prevent scapegoating or to make sense of an impasse in the group that mirrors what is happening in the therapy being discussed.

It is inevitable that trainees will make cognitive interventions with their psychodynamic cases or be drawn to think psychodynamically during CBT. They can gain considerably if the supervisor and group help them to identify and discuss possible psychodynamic, cognitive or systemic interventions in a way that encourages them to reflect and choose what to do and say rather than feel they have to get it 'right'. With their short cases it is essential that the trainees are active as therapists and go beyond being good listeners. Few texts specifically identify exactly what is meant by being active: reactive listening, demonstrating warmth and empathy, staying in the here and now and helping the patient to think about how to tackle problems. Yet it is rarely possible to help patients achieve change through brief work without taking an active stance.

Supervisors need to be firm and clear when it comes to dynamic administration: ensuring and protecting the continuity and privacy that enable therapeutic change to take place, regardless of the model of therapy. Trainees often need help in finding a suitable room, protecting their time with their patient and ensuring their continued availability as they rotate to new jobs. A supervisor should be sufficiently senior to be an effective advocate over such matters and can expect periodically to be triangulated with the trainee's consultant trainer - often in a way that mirrors the patient's or trainee's previous experience with attachment figures.

Psychodynamic therapists consider that all therapies work at least in part on the basis of attachment, although this is particularly difficult for inexperienced therapists to accept. Trainees will not be able to think in terms of transference, let alone make transference interpretations, until they can accept that they have become important to their patient and that this is normal, desirable and manageable. Like their patients, they often wonder how the therapy can come to a satisfactory end. Trainees undertaking brief, structured therapies such as interpersonal therapy or brief CBT are regularly astonished that it works and that, with

\section{Box 4 Guidelines for 'visiting' therapists}

- Update the information on how to contact you when you change posts

- Stick to the same day, time and room for each session

- Keep to the same length for each session even if your patient has little to say

- Arrive at least $5 \mathrm{~min}$ early for the session

- Do not remove the patient's notes from the department/unit

- Leave your pager elsewhere during the session

- Do not take notes during the session (except for CBT )

- File the patient's notes yourself after each session

- Warn your patient and supervisor at least 3 weeks ahead of any absence

- Dictate or draft in longhand any letters to your patient - there is no standard letter

- Do not discuss what your patient tells you, except in supervision

help, they can establish a therapeutic alliance and negotiate an ending. Supervisors have the benefit of considerable experience and, often, personal therapy. It is important that they help trainees sustain confidence in the effectiveness of therapy; this is by no means intuitively obvious.

At the end of a therapy, and particularly of their long case, trainees could be encouraged to write up the therapy. This can lead to a logbook entry but the true purpose lies in the concluding aspect of the task: considering what the trainee learnt from the experience. Other members of the supervision group can contribute and trainees should remain in the group until they have had a chance to digest their experience.

\section{Short cases}

Trainees are usually keen to take on short cases but psychotherapy tutors often have difficulty making the necessary arrangements. Delivering a brief psychodynamic or cognitive-behavioural therapy is an active process that requires careful formulation and planning and also intensive supervision. Supervisors may themselves need training and support to provide this supervision and, especially, to stay focused and to stick to the relevant model. This can be an issue for those CBT supervisors who mostly work in other fields such as general 
psychiatry. Clinical psychologists may be willing to supervise trainees if the patients seen come from their own waiting list.

Finding patients who both need and are suitable for brief work with an inexperienced therapist can be a challenge. As a matter of tact trainees should be encouraged to look for patients under their own consultant's care. Consultant trainers often need support and guidance in selecting appropriately; it can take some time to become good at this. This is where the psychotherapy tutor can help by advising on selection for psychotherapy - a very opaque matter for those not conducting therapies themselves. Consultant colleagues tend to select patients who strike them as needing more than treatment as usual and many of these will be people with borderline personality disorder, who need an experienced therapist. However, carers of patients, including those with dementia, may have sufficiently robust and stable personalities to benefit from brief interventions addressing loss. To locate suitable patients, tutors need to develop links with crisis and self-harm teams as well as with community mental health teams. Often this means that the tutor needs to be available on demand to discuss a potential case and act as link person for the patient until therapy starts. Trainees may have to be reminded that it is not in patients' interests to wait more than a short period for therapy, no matter how desirable it may be to have the next examination out of the way. There are inevitably issues such as where patients will be seen, whether or not they come under the care programme approach and who exactly is responsible for which aspects of care. This is why the coordinating tutor has to be local and needs the experience and authority of being a consultant psychiatrist in psychotherapy.

\section{CBT short cases}

It is hard work steering a novice therapist through a short CBT and it is best to select patients with depression - not dysthymia - or a focal behavioural problem, preferably of recent origin - not longstanding agoraphobia. Obsessive-compulsive disorder and bulimia should be referred on to more experienced therapists. Because CBT is cited as the treatment of choice in many guidelines, enthusiastic clinicians often refer without considering whether the patient is even prepared to attend, so the first step for trainee and supervisor is often to consider motivation.

\section{Integrative short cases}

Finding a case for brief integrative therapy may be less difficult for trainees and the coordinating psychotherapy tutor than identifying a supervisor for the therapy.

Interpersonal therapy is dynamically informed but cognitively delivered. It is designed as a brief, structured intervention for people with depression and at a basic level is easily grasped. Although a very useful intervention in community psychiatry, its adoption in the UK has been patchy and in only a few centres have practitioners of interpersonal therapy completed training as supervisors.

Cognitive analytic therapy is a more complex intervention which has changed and developed considerably since first developed by Ryle (Denman, 2001). Trainers in CAT are divided about its appropriateness as a training experience for trainees. A recent comparison of CAT $v$. brief psychodynamic therapy, both delivered by SHOs, found more variable outcomes with CAT (Mace et al, 2006). Although CAT is becoming more widely available in England, whether or not it is a training option depends very much on the willingness of local CAT specialists, usually clinical psychologists, to supervise psychiatric trainees.

Consultant psychiatrists can usually identify patients and provide supervision for supportive therapies. They may feel more confident as supervisors if given clear instructions on how many sessions are needed for a therapy to count towards the training requirements, what is expected of the trainee, the frequency and purpose of supervision and what sort of feedback the psychotherapy tutor will need. Brief, supportive therapies work well when based on a transition such as leaving school or home, becoming a parent, retirement, bereavement or discharge from an in-patient ward or residential facility. This provides a framework within which a time-limited therapy makes sense to the patient as well as the trainee and allows the therapy to be brought to a planned end. Adescription of supportive therapy can be found on the Northern Psychiatry Trainees' website (Brogan, 2006). Supportive therapy can be relevant for both patients and their relatives across the age range. Working with older patients can provide trainees with valuable insights, although patients need to be selected with care because a death during therapy can be traumatic for the novice therapist. Hildebrand (1995) and Porter et al (2004) are good and accessible texts that introduce the sort of issues that may preoccupy older patients.

\section{Psychodynamic short cases}

Brief psychodynamic work can also usefully be structured round transitions or loss. Many consultant psychiatrists in psychotherapy think it is easier for trainees to take on a brief psychodynamic case if they have previously completed a psychodynamic 
long case; they seem then to have more of a sense of what to do or, more crucially, what not to do, i.e. how to engage actively with the patient without being directive or unduly steering sessions.

\section{Group therapy}

Twenty-five years ago every psychiatric hospital had a range of therapeutic groups (Box 5) available for patients. These days, trainees may find it difficult even to participate in an anxiety management group and few wards maintain regular groups. So trainees may have to be directed to the voluntary sector or to user organisations for this experience. One alternative may be participation in 2-or 3-day group workshops such as those organised by the Institute of Group Analysis.

Psychotherapy tutors may feel defeated by the limited opportunities for trainees to gain group experience, but this training requirement could stimulate a modest revival of therapeutic group work. Psychological therapy services benefit from being able to offer patients focused, time-limited groups (e.g. for anxiety or depression management), both for their content and as a less demanding initial therapy experience for those who need to increase their motivation or psychological mindedness. With appropriate support and supervision, a cycle of regular, time-limited, closed groups can be developed, providing opportunities for trainees to participate in all aspects of a group, including selection of patients, making notes and reporting back to referrers. Stock Whittaker (2001) gives detailed advice on how to plan, establish and run a wide range of therapeutic groups.

Box 5 Examples of time-limited, closed groups

- Anxiety management

- Depression management

- Anger management

- Pre-discharge

- Psychoeducational groups for patients or carers

- Discussion of current affairs/gender issues

- Living with cancer

- Groups for relatives/partners of alcohol or drug misusers

- Bereavement

- Activity focused (e.g. cookery, gardening, art)

\section{Couple, family or systemic experience}

Sadly, few trainees now have the opportunity to participate in family work except in child or adolescent psychiatric posts. The development of new teams in assertive outreach, crisis resolution and early intervention in psychosis should offer new opportunities for trainees to develop a basic understanding of systemic approaches. The capacity to think systemically does not necessarily develop automatically and systemic therapy tends to be poorly covered by local training courses. College or clinical tutors may be prevailed upon to include introductory lectures on systemic thinking and its applications as part of the locality's regular educational programme.

\section{Conclusions}

A psychological therapies service will find that psychiatric trainees have a lot to offer: they are bright, enthusiastic and usually come to care deeply about their psychotherapy patients. Trusts are already performance managed on the proportion of patients being offered talking therapies. Matching up patients' and trainees' needs can extend the scope of therapy provided, improve a trust's profile with commissioners and strategic health authorities, and be a satisfying and enjoyable experience. But it takes energy, persistence and more time than most chief executives and medical directors realise.

\section{Declaration of interest}

S. M. chairs the Regional Psychotherapy Trainers' Committee for the Northern Deanery. She is also the local regional representative to the Executive Committee of Psychotherapy Faculty of the Royal College of Psychiatrists.

\section{References}

Balint, M. (1957) The Doctor, His Patient and the Illness. Reprinted 2000. Churchill Livingstone.

Bateman, A. \& Holmes, J. (1995) An Introduction to Psychoanalysis: Contemporary Theory and Practice. Routledge.

Blackwell, C. L. \& Rimmer-Yehudai, E. (2001) Midwives, fostermothers, stepmothers? Clinical psychologists teaching junior doctors psychotherapy. British Journal of Psychotherapy, 17, 530-543.

Bhugra, D. (2005) Training for consultants in 2020, response to Drs Mukherjee and Nimmagadda. Psychiatric Bulletin, 29, 46.

Bhugra, D. (2006) The Dean's Medical Education Newsletter. January 2006. Royal College of Psychiatrists (http://www.rcpsych. ac.uk/pdf/NewsletterJanuary\%202006.pdf).

Brogan, C. (2006) Psychotherapy Training. Northern Psychiatry Trainees. http://www.northernpsychiatrytrainees.com/?p=45 
Campbell, D. \& Hale, R. (2001) Suicidal acts. In Textbook of Psychotherapy in Psychiatric Practice (ed. J. Holmes), pp. 287306. Churchill Livingstone.

Carley, N. \& Mitchison, S. (2006) Psychotherapy training experience in the Northern Region Senior Unified SHO Scheme: present and future. Psychiatric Bulletin, 30, 390-393.

Das, A., Egleston, P., El-Sayeh, H., et al (2003) Trainees' experience of a Balint group. Psychiatric Bulletin, 27, 274-275.

Denman, C. (2001) Cognitive-analytic therapy. Advances in Psychiatric Treatment, 7, 243-252.

Duddu, V. \& Brown, P. M. (2004) Psychotherapy training in the Northwest - a survey. Psychiatric Bulletin, 28, 104-105.

Fitzgerald, G. \& Hunter, M. D. (2003) Organising and evaluating a Balint group for trainees in psychiatry. Psychiatric Bulletin, 27, 434-436.

Fraiberg, S., Adelson, S. \& Shapiro, V. (1980) Ghosts in the nursery: a psychoanalytic approach to the problems of impaired infantmother relationships. In Clinical Studies in Infant Mental Health: The First Year of Life (ed. S. Fraiberg), pp. 164-196. Tavistock.

Hildebrand, P. (1995) Beyond Mid-Life Crisis. Sheldon Press.

Ikkos, G. (2003) Engaging patients as teachers of clinical interview skills. Psychiatric Bulletin, 27, 312-315.

Mace, C., Beeken, S. \& Embleton, J. (2006) Beginning therapy: clinical outcomes in brief treatments by psychiatric trainees. Psychiatric Bulletin, 30, 7-10.

Malan, D. (1979) Individual Psychotherapy and the Science of Psychodynamics. Butterworth-Heinemann.

Miller, L. (1999) Babyhood: becoming a person in the family. In Personality Development: A Psychoanalytic Perspective (eds D. Hindle \& M. V. Smith), pp. 33-47. Routledge.

Porter, R., Evans, S. \& Garner, J. (2004) Talking Over the Years: A Handbook of Dynamic Psychotherapy with Older Adults. BrunnerRoutledge.

Rogers, C. R. (1951) Client-Centred Therapy: Its Current Practice, Implications and Theory. Constable \& Robinson.

Royal College of Psychiatrists (2004) Requirements for Psychotherapy Training as Part of Basic Specialist Training. Royal College of Psychiatrists (http:/ / www.rcpsych.ac.uk/PDF/ptBasic.pdf).

Segal, J. (1986) Phantasy in Everyday Life: A Psychoanalytical Approach to Understanding Ourselves. Karnac.

Stock Whittaker, D. (2001) Using Groups to Help People (2nd edn). Brunner-Routledge.

Watts, D. \& Morgan, G. (1994) Malignant alienation. Dangers for patients who are hard to like. British Journal of Psychiatry, 164, 11-15.

Wildgoose, J., McCrindle, D. \& Tillett, R. (2002) The Exeter halfday release psychotherapy training scheme - a model for others? Psychiatric Bulletin, 26, 31-33.

\section{MCQs}

1 The Royal College of Psychiatrists requires:

a trainees to conduct three short cognitive-behavioural therapies

$\mathrm{b}$ case discussion groups to be led by psychiatrists

c local psychotherapy tutors to be consultant psychiatrists in psychotherapy

d trainees to become competent at making psychodynamic formulations

e all trainees to have experience of supportive therapy.

2 Trainees:

a make cognitive interventions in psychodynamic cases

$\mathrm{b}$ are usually confident that their therapy will be successful c should take notes for supervision during therapy

$\mathrm{d}$ are rarely highly motivated therapists

e learn more readily from their supervisors than from each other.

3 As regards psychotherapy:

a family therapy is provided by most psychological therapy services

b interpersonal therapy is suitable only for patients with interpersonal problems

c brief, supportive therapy is rarely suitable for adolescents

d brief supportive therapy is often suitable for adolescents

e consultants in general adult psychiatry need special training to supervise supportive therapy.

4 Psychotherapy tutors:

a should encourage trainees to draw their short cases from their consultant's case-load

b can usually include visiting medical students in case discussion groups

c should insist that case discussion and supervision are pager-free times

d often find suitable patients for brief psychodynamic therapies without assistance

e should refrain from advising consultant colleagues whom to refer for brief therapy.

5 Psychotherapy supervisors:

a should assist trainees to work out practicalities for their therapies

b should allow trainees to learn from their own mistakes without too much direction

c should be full-time, practising therapists

d should encourage trainees to alter the time of sessions to fit around their patients' changing requirements

e should not allow other trainees to point out basic errors to a new trainee.

\begin{tabular}{|llllll|}
\hline \multicolumn{2}{|l}{ MCQ answers } & & & \\
1 & & 2 & 3 & 4 & 5 \\
a F & a T & a F & a T & a T \\
b F & b F & b F & b F & b F \\
c F & c F & c T & c F & c F \\
d T & d F & d F & d F & d F \\
e F & e F & e F & e F & e F \\
\end{tabular}

